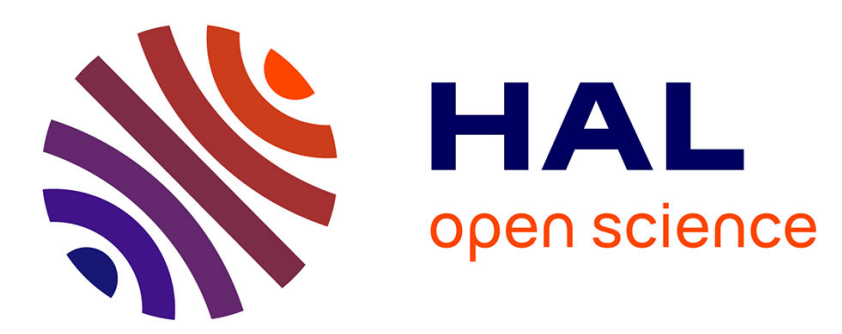

\title{
Comparing the cost of adjuvant anastrozole with the benefits of managing less patients with relapsed breast cancer
}

\author{
R. J. Thomas, M. Williams, J. Glen, M. Callam
}

\section{- To cite this version:}

R. J. Thomas, M. Williams, J. Glen, M. Callam. Comparing the cost of adjuvant anastrozole with the benefits of managing less patients with relapsed breast cancer. Breast Cancer Research and Treatment, 2009, 117 (2), pp.289-295. 10.1007/s10549-008-0289-6 . hal-00535325

\section{HAL Id: hal-00535325 \\ https://hal.science/hal-00535325}

Submitted on 11 Nov 2010

HAL is a multi-disciplinary open access archive for the deposit and dissemination of scientific research documents, whether they are published or not. The documents may come from teaching and research institutions in France or abroad, or from public or private research centers.
L'archive ouverte pluridisciplinaire HAL, est destinée au dépôt et à la diffusion de documents scientifiques de niveau recherche, publiés ou non, émanant des établissements d'enseignement et de recherche français ou étrangers, des laboratoires publics ou privés. 


\title{
Comparing the cost of adjuvant anastrozole with the benefits of managing less patients with relapsed breast cancer
}

\author{
R. J. Thomas $\cdot$ M. Williams $\cdot$ J. Glen $\cdot$ \\ M. Callam
}

Received: 6 October 2008/Accepted: 10 December 2008/Published online: 3 January 2009

(C) Springer Science+Business Media, LLC. 2009

\begin{abstract}
Prescribing anastrozole instead of tamoxifen increases initial adjuvant drug costs but there is an eventual saving as fewer patients will relapse. The effect of this saving depends on an accurate understanding of the cost of breast cancer relapse. We identified 232 patients relapsing between March 2000 and 2005. Seventy-seven were randomly selected for analysis of their entire hospital and community management costs from the date of relapse until death, or the end of the evaluation period (01/01/07). The mean cost per patient was $£ 25,186$ (95\% CI $£ 13,705-£ 33,821)$. The median survival from time of relapse was 40.07 months (range 0.5-73 months) and median total cost per patient was $£ 31,402.62$. Equating this figure with the difference in relapse rate $(4.1 \%)$, initial drug cost $(£ 4,773)$ gives an extra cost of $£ 17,244 /$ life year saved. This was the first adjuvant cost effectiveness analysis which included the community management activity of a subsequent relapse.
\end{abstract}

Keywords Relapse - Breast cancer - Cost-effectiveness . Anastrozole

R. J. Thomas $(\bowtie) \cdot$ M. Williams $\cdot$ M. Callam

The Primrose Oncology Research Unit, Bedford Hospital

NHS Trust, Bedford MK42 9DJ, UK

e-mail: rt@cancernet.co.uk

\section{R. J. Thomas}

Addenbrooke's Hospital, Cambridge University NHS Trust, Cambridge CB2 2QQ, UK

R. J. Thomas · J. Glen

Department of Economics, Cranfield University,

Bedfordshire MK43 0AL, UK

\section{Introduction}

Developments in adjuvant drugs such as trastuzumab, aromatase inhibitors and taxanes are giving clinicians and patients several choices following a diagnosis of early breast cancer. The Arimidex, Tamoxifen, Alone or in Combination (ATAC) trial showed that anastrozole, given from diagnosis for 5 years, improved disease-free survival by $4.1 \%$ compared to 5 years tamoxifen (100 months median follow up data) [1]. Other adjuvant aromatase inhibitors studies have shown similar benefits [2-4]. These strategies, although initially expensive, reduce the risk of relapse and hence involve long-term cost savings [5]. The challenge for budget holders is to contrast the long-term fiscal gain against the higher initial costs. Notwithstanding the humanitarian issues, the key to this comparison is an accurate estimate of how much it costs to treat a patient who has relapsed. Patients require regular hospital attendances, intensive drug treatments including chemotherapy, hormone therapy, immunotherapy and analgesia, not to mention radiology, pathology and radiotherapy in addition to the enormous community support with general practitioners (GPs), district nurses and palliative care services.

Health economic analyses of anastrozole have been conducted in the past [6], but all estimate the cost of a relapse using predictive modelling, questionnaires or interviews with clinicians [2, 3, 7-9]. An independent United Kingdom (UK) trial, now 6 years old, estimated hospital costs of relapsed breast cancer by sending questionnaires to UK oncologists, and estimated a cost of $£ 12,500$ per patient $[10,11]$. A comprehensive study from Edinburgh, estimated a cost of $£ 13,533$ for loco-regional relapse and $£ 13,193$ for distant relapse, but collected hospital data alone, from node positive women. [12, 13]. This study reports the first analysis of the complete hospital and 
community costs of managing patients with relapsed breast cancer, based on actual data from a typical UK breast cancer practise.

\section{Methods}

The Bedford Breast Unit database identified 232 women with breast cancer who had relapsed between March 2000 and 2005, with loco-regional or distant disease. The patients' hospital numbers were placed in separate sealed envelopes, shuffled, and one-third (77) randomly selected by an independent worker, for detailed data collection. Data was collected until a patient's death or the predetermined end of the study in January 2007. Table 1 summarises the demographics of the entire group and selected cohort, their similarity indicating that the randomisation process was balanced. The specific cancer-related activities were derived from hospital notes, and computer, pharmacy, GP, district nurse and hospice records. Activities included; in-and outpatient activity, oncology drugs, radiology, radiotherapy, blood tests investigations, GP, district nurse and hospice visits (Table 2). There were no missing data, as the research team visited all GP practises, hospices, community offices and hospital departments, and ensured that all available data were collected.
Analysis and statistical considerations

The data were analysed in liaison with the Health Economics Department at Cranfield University. The median life expectancy was measured from a Kaplan-Meier life table and survival curve (Fig. 1). Cross-checking using the XLSTAT package for consistency and normality, suggested that the distribution of the average cost per month was nonnormal and under such circumstances the median, rather than mean, was deemed a better representation. The predetermined subgroups were oestrogen receptor (ER) positivity (Allred score $>4$ ); human epidermal growth factor receptor 2 (HER2) over-expression; axillary node involvement and menopausal status (defined as no spontaneous mensus for 2 years, lutinising hormone, follicle stimulating hormone and oestrodiol levels or if uncertain, aged over 55 years). For comparison of the direct cost between the subgroups, the mean cost per patient was more representative.

The tariffs

The tariffs of the UK National Health Service (NHS) procedures, outpatient visits, nights in hospital and investigations were deduced from the existing NHS Reference Costs [14]. Radiotherapy cost per fraction was based on the national average unit cost [14]. GP and district nurse visits costs were
Table 1 Demographics of the relapsed patients between March 2000 and 2005

\begin{tabular}{lccl}
\hline $\begin{array}{l}\text { At presentation } \\
\text { of initial breast cancer }\end{array}$ & $\begin{array}{l}\text { All relapsed } \\
\text { patients } 232(\%)\end{array}$ & $\begin{array}{l}\text { Study cohort } \\
77(\%)\end{array}$ & $\begin{array}{l}\text { Difference } \\
\text { (significance) }\end{array}$ \\
\hline Average age & $60.5(31-95)$ & $62.3(33-95)$ & $\mathrm{ns}$ \\
Invasive ductal & $166(72 \%)$ & $56(73 \%)$ & $\mathrm{ns}$ \\
Invasive lobular & $28(12 \%)$ & $14(17 \%)$ & $\mathrm{ns}$ \\
Unknown & $38(16 \%)$ & $7(9 \%)$ & $\mathrm{ns}$ \\
Node positive & $119(51 \%)$ & $34(44 \%)$ & $\mathrm{ns}$ \\
Node negative & $67(29 \%)$ & $36(47 \%)$ & $\mathrm{ns}$ \\
Node unknown & $46(20 \%)$ & $7(9 \%)$ & $\mathrm{ns}$ \\
T0 & $2(1 \%)$ & $2(3 \%)$ & $\mathrm{ns}$ \\
Stage T1 & $87(37.5 \%)$ & $36(48 \%)$ & $\mathrm{ns}$ \\
Stage T2 & $87(37.5 \%)$ & $26(33 \%)$ & $\mathrm{ns}$ \\
Stage T3-4 & $40(17 \%)$ & $13(16 \%)$ & $\mathrm{ns}$ \\
Tis (in situ) & $7(3 \%)$ & $0(0 \%)$ & $\mathrm{ns}$ \\
Unknown & $9(4 \%)$ & $2(3 \%)$ & $\mathrm{ns}$ \\
Post menopausal & $147(63 \%)$ & $52(67 \%)$ & $\mathrm{ns}$ \\
Pre-menopausal & $69(30 \%)$ & $25(33 \%)$ & $\mathrm{ns}$ \\
Male & $0(0 \%)$ & $0(0 \%)$ & $\mathrm{ns}$ \\
ER & $97(42 \%)$ & $30(39 \%)$ & $\mathrm{ns}$ \\
ER & -ve & $16(20 \%)$ & $\mathrm{ns}$ \\
ER unknown & $79(34 \%)$ & $31(41 \%)$ & $\mathrm{ns}$ \\
\hline
\end{tabular}


Table 2 Categories of costs following relapse (77 patients)

\begin{tabular}{|c|c|c|c|c|c|}
\hline & Source & $95 \%$ со & & Mean & Total $(£)$ \\
\hline \multicolumn{6}{|l|}{ Community costs } \\
\hline GP home visit & GPDB & 301 & 657 & 479.87 & 36,950 \\
\hline GP appointments & GPDB & 772 & 1,469 & $1,121.26$ & 86,337 \\
\hline GP telephone calls & GPDB & 57 & 109 & 83.53 & 6,432 \\
\hline Hospice nights & GPBD & 495 & 1,796 & $1,145.99$ & 88,241 \\
\hline Hospice visits & HDB & 25 & 118 & 72.13 & 5,554 \\
\hline Palliative community telephone & HBD & 39 & 86 & 62.65 & 4,824 \\
\hline Palliative community visits & HDB & 272 & 811 & 542.12 & 41,743 \\
\hline Community district nurse & INR & 98 & 762 & 430.18 & 33,124 \\
\hline GP prescribed drugs & GPDB & 2,350 & 4,481 & $2,915.7$ & 263,036 \\
\hline Hospice drugs & $\mathrm{HN}$ & 70 & 614 & 272.13 & $20,953.99$ \\
\hline Sub total community costs & & 4,479 & 10,903 & 7,123 & $£ 587,195$ \\
\hline Percentage total cost $(£ 1,939,329)$ & & & & & $30.3 \%$ \\
\hline \multicolumn{6}{|l|}{ Hospital drugs } \\
\hline Outpatients hospital pharmacy & PDB & 3,839 & 7,940 & $5,889.55$ & $453,495.41$ \\
\hline Ward stores & PDB & 47 & 367 & 207.32 & $15,963.33$ \\
\hline \multicolumn{6}{|l|}{ Hospital bed costs } \\
\hline In-patients & PIMS & 2,166 & 3,802 & $2,984.27$ & 229,789 \\
\hline Surgical interventions & PIMS & 733 & 1,489 & $1,111.73$ & $85,603.12$ \\
\hline Blood transfusion & $\mathrm{HN}$ & 372 & 1,044 & 708.23 & 54,534 \\
\hline \multicolumn{6}{|l|}{ Out-patients visits } \\
\hline Outpatient consultation & PIMS & 2,471 & 3,602 & 3,037 & 233,849 \\
\hline Day/half-day case & PIMS & 1,040 & 1,981 & $1,511.06$ & 116,352 \\
\hline Electrocardiogram (ECG) & DR HN & 41 & 83 & 62.88 & 4,842 \\
\hline Radiotherapy & RTDB & 408 & 764 & 586.57 & 45,166 \\
\hline Support services & DR HN & 48 & 106 & 77.68 & 5,981 \\
\hline Accident and emergency admissions & PIMS & 129 & 213 & 171.53 & 13,208 \\
\hline \multicolumn{6}{|l|}{ Hospital services } \\
\hline Radiology & DDB & 554 & 856 & 705.47 & $54,321.64$ \\
\hline Pathology & DDB & 292 & 459 & 376.2 & $28,967.04$ \\
\hline Transport & DR & 44 & 216 & 130.68 & 10,062 \\
\hline Sub total of hospital costs & & 9,226 & 22,918 & 17,560 & $£ 1,352,134$ \\
\hline Percentage of total costs $(£ 1,939,329)$ & & & & & $69.7 \%$ \\
\hline Grand total & & 13,705 & 33,821 & 25,186 & $£ 1,939,329$ \\
\hline
\end{tabular}

Key: PIMS Patient Information Management System. $H N$ official printed or written notes. RTBD Addenbrooke's oncology electronic data base. $D R$ departmental records (manual). $D D B$ department database. $P D B$ pharmacy database. GPDB General practise database. INR individual nursing records

taken from primary care trust reference costs [14]. Hospital drug costs included value added tax (VAT), and were the actual amount charged for each. Community drug tariffs (excluding VAT) and hospice drug tariffs (including VAT) were based on the British National Formulary [15].

\section{Results}

Of the 77 patients whose data sets were analysed in this study, $52(67.5 \%)$ had died of metastatic breast cancer by the end of the data collection point, January 2007, with a median survival of 3.34 years, (40.07 months, Fig. 1). The first site of relapse was distant in 51 patients (66\%), and loco regional in $26(34 \%)$. The average time from initial diagnosis to relapse was 71.2 months (range 4-173 months).

The total hospital and community cost of managing the 77 patients from the time of their relapse until death or to the end of the evaluation period was $£ 1,939,329$. Based on the total number of patient-months within the assessment period 


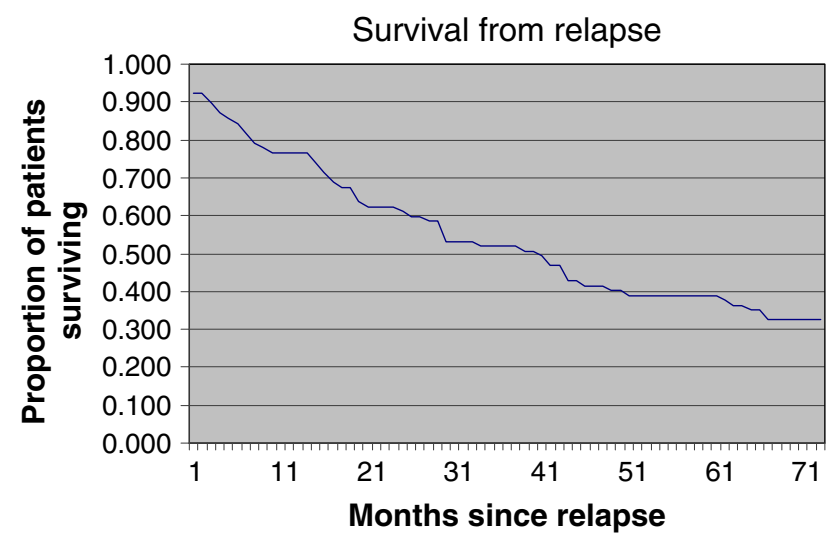

Fig. 1 Survival curve for 77 patients from date of relapse. Median survival 40.07 months ( 25 were alive at the time of the analysis)

$(2,474.6)$, the average cost was $£ 783.7$ per patient-month. Based on the median survival (40.07 months), the median cost per patient was $£ 31,403$.

Nearly a third (30.3\%) of the cost of a relapse lay in the community, and $69.7 \%$ in the hospital setting. There was no difference in those axillary node positive or negative patients, or between HER2 over-expressers or not, but in this study cohort only 7 of the 16 HER2 over-expressers received trastuzumab.

This cost of relapse data can be used to estimate the cost-effectiveness of adjuvant anastrozole. Based on the absolute difference in disease-free survival at 10 years post-randomisation, between 5 years adjuvant tamoxifen or 5 years adjuvant anastrozole was $4.1 \%$ [1], the number needed to be treated to avoid one relapse was 24.4 patients $(1 / 4.1 \%)$. Table 3 demonstrates the extra initial costs of anastrozole over tamoxifen based on national tariffs. The difference in drug and bone density costs between 5 years tamoxifen and 5 years anastrozole strategies was $£ 4,773$ [15]. Consequently it costs $£ 116,415$ to prevent one patient relapsing. However, subtracting the median cost of treating

Table 3 Summarises compares the cost of anastrozole strategies over tamoxifen alone

\begin{tabular}{llll}
\hline $\begin{array}{l}\text { Costs per } \\
\text { patient }\end{array}$ & $\begin{array}{l}\text { 5 years } \\
\text { treatment with } \\
\text { tamoxifen }\end{array}$ & $\begin{array}{l}\text { 5 years } \\
\text { treatment with } \\
\text { anastrozole }\end{array}$ & $\begin{array}{l}\text { 2 years } \\
\text { tamoxifen } \\
\text { then 3 years } \\
\text { anastrozole }\end{array}$ \\
\hline $\begin{array}{l}\text { Drug } \\
\text { Bone density }\end{array}$ & $£ 135$ & $£ 4,468$ & $£ 2,735$ \\
scans (£110) & & $£ 440$ (4 scans) & $£ 220$ (2 scans) \\
Total AI strategy & $£ 0$ & $£ 4,908$ & $£ 2,955$ \\
Extra initial cost & $£ 0$ & $£ 4,773$ & $£ 2,681$ \\
\hline
\end{tabular}

T-Tamoxifen, A-Anastrozole. The costs displayed assume no dropouts or lowering in the price of the drug over time. The drugs prices are from the British National Formulary list tariffs ( $£ 68.56$ per 28 days) a patient with relapsed breast cancer gained from this study ( $£ 31,403$ ), gives net cost estimate of $£ 85,012$, or $£ 3,485$ per patient treated with anastrozole.

The median survival of the relapsed women in this study was 2.72 years, but in order to calculate the cost per life year gained, it was necessary to estimate the life expectancy of patients who do not relapse compared to those who do. This was estimated using a Markov Model and fitting Weibull Curves to the analysis of the ATAC trial (68 months data) [6]. This methodology required a key assumption that the benefit of anastrozole would carry over to 5 years following the end of treatment, which was later verified in the ATAC trial (100 months data) publication [1]. Extrapolated over 25 years, the life expectancy of a representative 64 years old female who did not suffer a breast cancer relapse was 13.01 years compared to 8.08 years for a female who did suffer a relapse. The estimated difference in life expectancy between relapsed and non-relapsed patients is therefore 4.93 years. The estimated incremental cost to prevent a breast cancer relapse if anastrozole is used upfront for 5 years instead of tamoxifen, is $£ 17,244$ per patient life year gained.

\section{Discussion}

The strength of this retrospective study lies in the comprehensiveness of the data extracted from a breast cancer population treated within a standard UK management framework. Collecting the complete data, from both hospital and community sources, required an enormous degree of co-operation from a wide range of professional groups. This could only practically be possible around a single institution. Paradoxically, this is also the basis of a potential criticism, as a single-institution study may be subject to skews in local population demographics or medical practise.

The demographics of the North Bedfordshire population appear to be fairly typical for the UK. The average age was similar to the national average, as was the single, separated and widowed population. The percentage of people with British citizenship (91.4 vs. 87.5\%), and those born in the UK (93.0 vs. $91.1 \%$ ) were also similar. There was a slightly higher percentage of the population working (42.6 vs. $40.1 \%$ ), and fewer unemployed (2.6 vs. $3.4 \%$ ), but a similar percentage who achieved higher educational qualifications (18.9 vs. $19.8 \%$ ) [16]. Breast cancer management adhered to West Anglia Cancer Network guidance, which has been developed from national advisory documents [17]. Any deviation from this guidance would require formal discussion and written approval, which has been established for 9 years.

The median overall survival for the patients relapsing at our institution (40.7 months), was higher than the 10-20 months 
reported with first-line metastatic studies in the UK and Europe evaluating metastatic chemotherapy regimens $[18$, 19], but it was fairly comparable with the 20-30 months reported within first-line metastatic aromatase versus tamoxifen studies $[9,20]$.

Although the median figure of $£ 31,403$ (Table 4) for treating a relapse is higher than previous UK estimates, the data is more recent and included the $30 \%$ of the community cost not previously collected. The results represent the last 6 years of management activity, and are therefore likely to underestimate future costs. Newer biological agents such as oral tyrosine kinase inhibitors and anti-angiogenesis drugs will substantially add to drug costs, but as they keep relapsed patients alive for longer, this will also increase non-drug costs. Even the full impact of trastuzumab, in this data set, was not fully appreciated. Routine use of trastuzumab in the metastatic setting within our institution was introduced in November 2006; almost half way through the evaluation period. This meant that only 7 of the 16 HER2 over-expressing patients received trastuzumab as part of their metastatic management. The average cost of the trastuzumab in the treated patients was $£ 15,834.62$. According to the original published metastatic breast cancer trastuzumab trials data, these patients on average, could have lived 5 months longer [21, 22]. Therefore, if the remaining nine patients had received trastuzumab, and each lived 5 months longer, this factor alone would have increased the total cost per patient to over $£ 34,200$.

The estimated cost per life year gained if anastrozole is used at upfront for 5 years instead of tamoxifen, compares favourably to the threshold used by the National Institute of Clinical Excellence of $£ 30,000$ per quality adjusted life year [23]. However, this is a simple analysis and assumes that patients receive all 5 years of treatment with anastrozole or tamoxifen, whereas in practise some patients would relapse within the first 5 years and thus would not receive the full 5 years worth of treatment. Taking this into account would decrease the incremental cost per life year gained. In addition, the analysis does not take into account differences in the adverse event profiles between the two drugs.
Although extrapolation of the data can provide a useful forecast, it highlights the pitfalls of costing studies. Newer and better drugs for the treatment of metastatic disease are constantly emerging, creating costly new challenges. Nevertheless, the cost per patient of adjuvant anastrozole seems very reasonable considering the devastation caused by a breast cancer relapse. In daily clinical practise, the cost-effectiveness of anastrozole may also be greater as many UK oncologists often select patients who have a good prognosis, and who could switch from tamoxifen at 2 years, as in the ARNO study. These include patients who do not have pathological prognostic factors which predict a higher and earlier relapse rate, such as higher histological grade, presence of vascular invasion, tumour size and number of positive axillary nodes [24], and biological molecular markers such Cerb2, Ki67, CYP-2D6, level of oestrogen receptor positivity and progesterone receptor negativity [24, 25]. However, even if patients have a good prognosis, patients may also be better off on anastrozole if they have a history of thromboembolic disease or risk of uterine carcinoma [24-26]. More recently, the roles played by quality of life, tolerance and patient preference also have important implications on the choice of adjuvant drug [5]. Nevertheless, despite these issues, there are savings to be made from delaying the start of anastrozole, although this may not be as great as anticipated. The difference in event-free survival between anastrozole and tamoxifen, albeit measured at 28 months post-switch and based on patients who have successfully completed $2-3$ years adjuvant therapy for early breast cancer. Based on the same methodology used in this study results in an incremental cost of $£ 11,173$ per life year. There are also some patients who relapse before 2 years, and who may not have done so if anastrozole was used upfront, and these patients are expensive to manage. Moreover, if the difference in eventfree survival was measured from the start of treatment, then the results may be different. As such, the results should not be used to support a treatment strategy of starting with tamoxifen with the intention of changing to anastrozole after two or more years, rather the results show a continuing cost advantage attached to using anastrozole after treatment with tamoxifen.

Table 4 Estimated cost to prevent one patient relapsing

\begin{tabular}{lll}
\hline Regimen & 5 years anastrozole $^{\mathrm{a}}$ & 2 years tamoxifen then 3 years anastrozole \\
\hline Cost to prevent one patients relapsing (extra cost/DFS) & $£ 116,414.6(4,773 / 4.1 \%)^{\mathrm{a}}$ & $£ 86,483.9(2,681 / 3.1 \%)^{\mathrm{b}}$ \\
Adjusted cost (subtract the cost of a relapse-£31,402.6) & $£ 85,012.0$ & $£ 55,081$ \\
Cost to prevent a relapse per life year (adjusted cost/4.93 years ${ }^{\mathrm{c}}$ ) & $£ 17,244$ per patient life year & $£ 11,173$ per patient life year \\
\hline a Disease free survival (DFS) figures from the ATAC trial at 100 months post-randomisation [1] \\
b ARNO trial [3] \\
c Difference in life expectancy between a relapsed and non-relapsed patients
\end{tabular}


This study's comprehensive estimate of the cost of relapse contributes to the body of published evidence, and adds accuracy and credence to the future of cost-effectiveness estimates of adjuvant breast cancer therapies. The already high, and escalating cost of treating patients with relapse breast cancer, confirms the humanitarian sentiments that it is better to prevent relapse in the first place. The authors intend to repeat the same data collection exercise every 2 years using the same methodology to give an ongoing estimate as the newer biological agents evolve into clinical practise.

Acknowledgments We would like to thank Bonny Parkinson, senior Health economist at AstraZeneca for her support in preparing this paper. The study was originally supported by an unrestricted education grant from Sanofi-Aventis and AstraZeneca. Roche Pharmaceuticals generously paid for the retrospective testing of HER-2 on histological tissue samples, where necessary. We would like to thank Habib Carfare (Breast Surgeon, Bedford Hospital), Brendan O'Sullivan (Chief Pharmacist Oncology, Addenbrooke's Hospital), Nick Jones (Chief Pharmacist, Bedford Hospital), Juliet Morris (Trials Pharmacist, Bedford Hospital), Elizabeth Wiggins (Breast Specialist Nurse and Database Coordinator), the patient advisors within Bosom Pals, the North Bedfordshire general practitioners, hospice, district and Macmillan nurses, all of who assisted with the data collection.

\section{References}

1. Forbes JF, Cuzick J, Buzdar A, Tobias JS, Baum M (2008) Arimidex, Tamoxifen, Alone or in Combination (ATAC) Trialists' Group. Effect of anastrozole and tamoxifen as adjuvant treatment for early-stage breast cancer: 100 months analysis of the ATAC trial. Lancet Oncol 9(1):45-53. doi:10.1016/S14702045(07)70385-6

2. Coombes RC, Hall E, Gibson L, Paridaens R, Jassem J et al (2004) A randomized trial of exemestane after two to three years of tamoxifen therapy in postmenopausal women with primary breast cancer. N Engl J Med 350(11):1081-1092. doi:10.1056/ NEJMoa040331

3. Jakesz R, Jonat W, Gnant M et al (2005) Switching of postmenopausal women with endocrine-responsive early breast cancer to anastrozole after 2 years' adjuvant tamoxifen: combined results of ABCSG trial 8 and ARNO 95 trial. Lancet 366(9484):455-462. doi:10.1016/S0140-6736(05)67059-6

4. Breast International Group (BIG) 1-98 Collaborative Group, Thürlimann B, Keshaviah A, Coates AS, Mouridsen H, Mauriac L, Forbes JF et al (2005) A comparison of letrozole and tamoxifen in postmenopausal women with early breast cancer. N Engl J Med. 353:2747-2757

5. Thomas R, Green J, Callam M (2006) Adjuvant breast cancer drugs-blockbusters or bankrupters? Br J Canc Manag 2(3):5-9

6. Mansel R, Locker G, Fallowfield L, Benedict A, Jones D, on Behalf of the ATAC Trialists' Group (2007) Cost-effectiveness analysis of anastrozole versus tamoxifen in adjuvant therapy for early stage breast cancer in the United Kingdom: the 5 years completed treatment analysis of the ATAC ('Arimidex', Tamoxifen alone or in combination) trial. Br J Cancer 97:152161. doi:10.1038/sj.bjc.6603804

7. Baum M, ATAC Trialists' Group (2002) The ATAC ('Arimidex', Tamoxifen, Alone or in Combination) adjuvant breast cancer trial in postmenopausal patients: factors influencing the success of patient recruitment. Eur J Cancer 38(15):1984-1986. doi:10.1016/ S0959-8049(02)00154-5

8. Boccardo F, Rubagotti A, Puntoni M, Guglielmini P et al (2005) Switching to anastrozole versus continued tamoxifen treatment of early breast cancer: preliminary results of the Italian tamoxifen anastrozole trial. J Clin Oncol 23(22):5138-5147. doi:10.1200/ JCO.2005.04.120

9. Mouridsen H, Gershanovich M, Sun Y, Pérez-Carrión R et al (2001) Superior efficacy of letrozole versus tamoxifen as first-line therapy for postmenopausal women with advanced breast cancer: results of a phase III study of the International Letrozole Breast Cancer Group. J Clin Oncol 19(10):2596-2606

10. Remak E, Brazil L (2004) Cost of managing women presenting with stage IV breast cancer in the United Kingdom. Br J Cancer 91(1):77-83. doi:10.1038/sj.bjc.6601890

11. Skedgel C, Rayson D, Dewar R, Potvin K, Younis T (2005) Economic evaluation of adjuvant hormonal options in post menopausal women with breast cancer: tamoxifen versus tamoxifen, then exemestane versus anastrozole. J Clin Oncol 23(16s): 538 Abstract number 6040

12. Karnon J, Kerr GR, Jack W, Papo NL, Cameron DA (2007) Health care costs for the treatment of breast cancer recurrent events: estimates from a UK-based patient-level analysis. Br J Cancer 97(4):479-485. doi:10.1038/sj.bjc.6603887

13. Wolowacz S, Roskell N, Christie A, Kerr G, Cameron D (2005) The cost of hospital care for relapsed breast cancer in the UK based on a large patient-level resource utilisation dataset. Presented at the European Conference of the International Society for Pharmacoeconmics and Outcomes Research, Florence

14. Department of Health (7 March 2005) NHS Reference Costs 2004. Available via http://www.dh.gov.uk. Accessed 17 June 2008

15. British National Formulary (June 2007) Pharmaceutical Press, BMJ Publishing Group Ltd, London

16. Office for National Statistics Census 2001: Bedfordshire County. Available via: http://www.statistics.gov.uk/census2001/profiles/ 9.asp. Accessed 17 June 2008

17. West Anglia Cancer Network Available via http://www.wacn. org.uk. Accessed 17 June 2008

18. Bontenbal M, Creemers GJ, Braun HJ et al (2005) Phase II to III study comparing doxorubicin and docetaxel with fluorouracil, doxorubicin, and cyclophosphamide as first-line chemotherapy in patients with metastatic breast cancer: results of a Dutch Community Setting Trial for the Clinical Trial Group of the Comprehensive Cancer Centre. J Clin Oncol 23(28):7081-7088. doi:10.1200/JCO.2005.06.236

19. Martin M, Villar A, Sole-Calvo A, Gonzalez R, Massuti B et al (2003) Doxorubicin in combination with fluorouracil and cyclophosphamide (i.v. FAC regimen, day 1, 21) versus methotrexate in combination with fluorouracil and cyclophosphamide (i.v. CMF regimen, day 1,21) as adjuvant chemotherapy for operable breast cancer: a study by the GEICAM group. Ann Oncol 14(6):833-842. doi:10.1093/annonc/mdg260

20. Nabholtz JM, Buzdar A, Pollak M, Harwin W et al (2000) Anastrozole is superior to tamoxifen as first-line therapy for advanced breast cancer in postmenopausal women: results of a North American multicenter randomized trial. Arimidex Study Group. J Clin Oncol 18(22):3758-3767

21. Vogel CL, Cobleigh MA, Tripathy D, Gutheil JC et al (2002) Efficacy and safety of trastuzumab as a single agent in first-line treatment of HER2-overexpressing metastatic breast cancer. J Clin Oncol 20(3):719-726. doi:10.1200/JCO.20.3.719

22. Slamon DJ, Leyland-Jones B, Shak S, Fuchs H et al (2001) Use of chemotherapy plus a monoclonal antibody against HER2 for metastatic breast cancer that overexpresses HER2. N Engl J Med 344:783-792. doi:10.1056/NEJM200103153441101 
23. National Institute for Health and Clinical Excellence (June 2008) Guide to the Methods of Technology Appraisal. Available via http:// www.nice.org.uk/media/B52/A7/

TAMethodsGuideUpdatedJune2008.pdf. Accessed 16 July 2008

24. Mauriac L, Keshaviah A, Debled M, Mouridsen H et al (2007) Predictors of early relapse in postmenopausal women with hormone receptor +ve breast cancer in the BIG-1-98 trial. Ann Oncol 18:859-867. doi:10.1093/annonc/mdm001

25. Ellis MJ, Coop A, Singh B, Mauriac L et al (2001) Letrozole is more effective neoadjuvant endocrine therapy than tamoxifen for
Erb B-1 and/or ErbB-2 positive, ER + ve primary breast cancer: evidence from a phase III randomised trial. J Clin Oncol 19(18): 3808-3816

26. Lønning PE, Geisler J, Krag LE, Erikstein B (2005) Effects of exemestane administered for 2 years versus placebo on bone mineral density, bone biomarkers, and plasma lipids in patients with surgically resected early breast cancer. J Clin Oncol 23(22):5126-5137. doi:10.1200/JCO.2005.07.097 